\title{
Paisajes transitivos. Caracterizando el potencial de los vacíos expectantes
}

\section{Josep Maria Solé Gras' ${ }^{1}$ Pau De Solà-Morales², Juan Manuel Zaguirre ${ }^{3}$}

Centre de Recerca Urbana del Camp (CRUC). Unidad Predepartamental de Arquitectura. Escuela

Técnica Superior de Arquitectura. Universitat Rovira i Virgili. Reus, Tarragona, España

E-mail: 1josepmaria.sole@urv.cat, ${ }^{2}$ pau.desolamorales@urv.cat, ${ }^{3}$ juanmanuel.zaguirre@urv.cat

\begin{abstract}
Resumen. Seducido por lo inquietante de su imagen de eterna espera, este trabajo pretende identificar, catalogar y sondear aquéllos vacios cuyo peso semiológico denota expectativa no cumplida. Busca explorar la condición perceptiva de la ausencia de una urbanidad reconocible y ahondar sobre los límites físicos y semánticos de estos ámbitos que derivan de la indecisión.

Numerosos autores han sucumbido ante sus encantos. Algunos, como Ignasi de Solà-Morales, acuñaban el término de terrain vague interrogando el significado de vacuum y emparentando la condición inherente de inestabilidad de estos lugares al concepto de promesa y libertad. Son los terrenos de la incertidumbre, los espacios burbuja, resultantes de una crisis económica y de modelo. Son aquellos ámbitos donde obsolescencia, programada ofortuita, los ha condenado a la duda. Son bordes e intersticios de unas infraestructuras omnipresentes, redundantes y confusa que dominan una periferia metropolitana y sobre cuya condición de ordinalidad y banalidad recae su valor ético y estético.

En este sentido, partiendo del reconocimiento de la latencia como condición contemporánea, este estudio ensaya elaborar una taxonomía del vacio expectante del Camp de Tarragona usando, tal fuera Aby Warburg, únicamente la imagen como soporte de investigación a partir de la construcción de un atlas de imágenes que ensaye la caracterización de la gramática territorial de estos paisajes transitivos.
\end{abstract}

Palabras clave: Periferia; Vacio; Paisaje transitivo; Urbanismo expectante; Terrain Vague

\section{Introducción}

"L'enthousiasme pour ces espaces vides, expectants, imprécis et fluctuants est, en code urbain, la réponse à notre étrangeté face au monde, face à notre ville, face à nous-mêmes"

Terrain Vague. De Solà-Morales, I. (1995)

Las distintas dinámicas de transformación de la ciudad tradicional, pausadas o convulsas, han sido histórica y sistemáticamente estudiadas desde varias disciplinas académicas como la arquitectura y el urbanismo, la sociología y antropología, la geografía o la economía. De manera continuada, cada uno de estos nichos de conocimiento ha sido capaz de desarrollar métodos propios para definir los conceptos y caracterizar las variables concretas que inciden en la ecuación urbana, así como elaborar proyecciones y escenarios de futuros que integren los posibles impactos derivados de una intervención concreta sobre el espacio. En otras palabras, las ciudades maduras, sobre todo en el contexto europeo, han confiado de manera decidida en herramientas como el Proyecto Urbano1 para liderar, desde la confianza en la Arquitectura como medio, la vivienda como unidad básica y el barrio como escala de referencia, el crecimiento y transformación de las urbes. 
No obstante, la realidad urbana, al menos en las últimas décadas, no ha resultado ser una ciencia tan exacta ni una fórmula tan precisa como se preconizó. En este sentido, la continua aparición de nuevas pulsiones sobre el territorio urbano ha demostrado ser un espacio estratégico donde conviven múltiples intereses -no siempre alineados ni compatibles-, un lugar de ritmos sincopados donde el vector temporal comprime escenarios o dilata estadios intermedios, un ámbito de fronteras inconcretas que condena, de manera irremediable, la clásica simplificación dicotómica del concepto campociudad y multiplica la aparición de situaciones híbridas de matices obligados. Con ello, el resultado no es otro que la dispersión, tanto conceptual como física, fruto de los procesos de metropolinización contemporánea de los territorios hacia espacios de transición donde la aproximación tradicional de los parámetros de productividad del suelo no permite resolver el entresijo de su situación de latencia.

Con ello, los territorios urbanos difuminan sus fronteras entre el cuerpo construido y el espacio libre e incorporan una serie de contextos intermedios, puestos en espera, donde la actividad que tradicionalmente le dio sentido e identidad -usualmente la agriculturafue súbitamente abandonada por la irrupción de un nuevo vector de interés que advenía una transformación radical de múltiples beneficios. En este sentido, la expectativa se afianza como principal motor de evolución de los paisajes cotidianos a la vez que incorpora el capital 2 como una nueva variable, intangible y de carácter mucho más volátil, en la ecuación territorial.

El resultado, la aparición de un rosario de ámbitos vacíos fruto del aparente estado de indecisión, lugares vacantes, expectantes de una realidad que no llega. Su rasgo más distintivo, seguramente, sea la doble condición de latencia y marginalidad que los convierte en espacios atrapados en el tiempo, al margen físico, ético y estético de aquellas dinámicas urbanas pretéritas que confiaban plenamente en los instrumentos del planeamiento como garantía de éxito.

Son paisajes de la contemporaneidad cuyas imágenes resultan ser tan bellas y potentes como inquietantes. En todas ellas, la semántica del vacío percibido denota, por un lado, la contradicción de la expectativa no cumplida y la carga de una frustración que pesadamente se convierte en una lenta y tácita aceptación mientras que, por el otro, insinúa de manera tímida el potencial de reinvención de dichos espacios como los verdaderos lugares de la innovación donde todo está por hacer. Son paisajes que susurran las posibilidades de especular conceptualmente sobre un ámbito vibrante e indeciso, que se escapa del control dominador que ejercen los poderes sobre la ciudad madura. Sin pretenderlo, estos lugares del olvido aparente son potenciales islas de libertad y creación.

Precisamente por esta condición ambigua, numerosos autores han sucumbido a los encantos de su estética visual y subversiva. Algunos, como Ignasi de Solà- Morales (1995), acuñaba el término de terrain vague3 interrogando conjuntamente los significados de los conceptos de extensión de suelo y vacío -derivado de vacuum-, emparentando, de manera inalienable, su inherente y compartida condición de inestabilidad a la vocación de promesa y libertad. Son, en cualquier caso, lugares de duda persistente que pueden reflejar, por medio de la mirada atenta de sus evocadoras imágenes de horizontes dominantes y carentes de límites precisos, el desasosiego y la extrañeza del ser metropolitano contemporáneo.

En este sentido, los refinados trabajos y testigos de los maestros como Robert Frank(The Americans,1962), Walker Evans (American Phoptographs, (1988), Jannes Linders (Stadslandschappen, 1986), John Davies (Temps et Paysage, 2000); David Plowder (Industrial Landscapes, 1985); Thomas Struth (Unconscious Places, 1980), Manolo Laguillo (Razón y Ciudad, 2013), Ursula SchulzDornburg (The Land in Between, 2018) o su propia hija, Julia Schulz- Dornburg (Ruinas modernas, una topografía del lucro, 2012) retratan, con gran eficacia, los aspectos más reveladores de la incertidumbre metropolitana a través de estos lugares obsoletos, amnésicos y marginales. Muestran, a través de su continua mirada, la evolución rota de estos espacios de borde, de aquellos intersticios de unas infraestructuras omnipresentes, redundantes y confusas 4 que dominan los territorios de una 


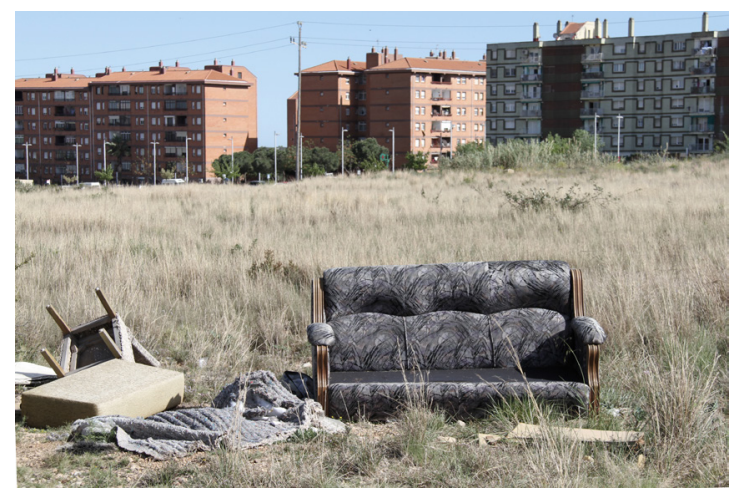

Fig. 1. (Imagen 1) Expecting landscapes (Solé, 2019)

periferia marginal mientras dibujan los paisajes de la inconsciencia. Este trabajo se fija, en definitiva, en aquellos espacios ordinarios (Walker, 2010) y banales (Muñoz, 2008) que, merced a su condición cotidiana, anodina, fragmentada, global (Sassen, 1991), residual y siempre anónima, plantean un nuevo relato metropolitano que parte de la incertidumbre de estos espaces autres (Foucault, 1966) u otros paisajes (Goula, 2006) como principal valor potencial de transformación de un territorio libre.(Imagen 1)

\section{Objetivo}

"De tels lieux n'existent pas, et c'est parce qu'ils n'existent pas que l'espace devient question, cesse d'être évidence, cesse d'être incorporé, cesse d'être approprié. L'espace est un doute: il me faut sans cesse le marquer, le désigner ; il n'est jamais à moi, il ne $m$ 'est jamais donné, il faut que j'en fasse la conquête"

Espèces d'espaces. Perec, G. (2000) inquietante de la imagen congelada en un presente perpetuo, de aparente espera eterna, esta investigación pretende identificar y sondear aquellos vacíos metropolitanos del Camp de Tarragona a través de la fotografía para, acto seguido, desvelar -revelar, en este caso- algunas de sus reglas y patrones que permitan caracterizar la especificidad de cada uno de estos paisajes transitivos.

En este sentido, con la mirada lejana puesta en la descubierta del potencial de transformación territorial de estos lugares, esta comunicación ha procurado permanecer en los estadios más primarios de la investigación, moviéndose todavía entre la conceptualización y la contextualización del problema confiando, por un lado, en la revisión sistemática de la literatura existente $y$, por otro lado, en la observación detallada y la intuición del objetivo fotográfico para construir, por medio de la colección de imágenes, su selección y posterior ordenación según parámetros de coherencia o contraste, un atlas del vacío, una topología inventariada de los paisajes expectantes que permita reconocer lógicas compartidas, estructuras similares y tiempos subyacentes.

No obstante, más allá de este objetivo primario, este estudio incorpora una serie de objetivos paralelos que se deberían complementar y compatibilizar con líneas de trabajo futuras que deberían poder concluir en una tesis doctoral. Entre ellos, cabe destacar:

- Ampliar la noción clásica de valor del paisaje tradicionalmente ligada a la condición pintoresca y reivindicar, con ello, la ordinalidad de la condición expectante como situación

Seducida por la componente sublime e

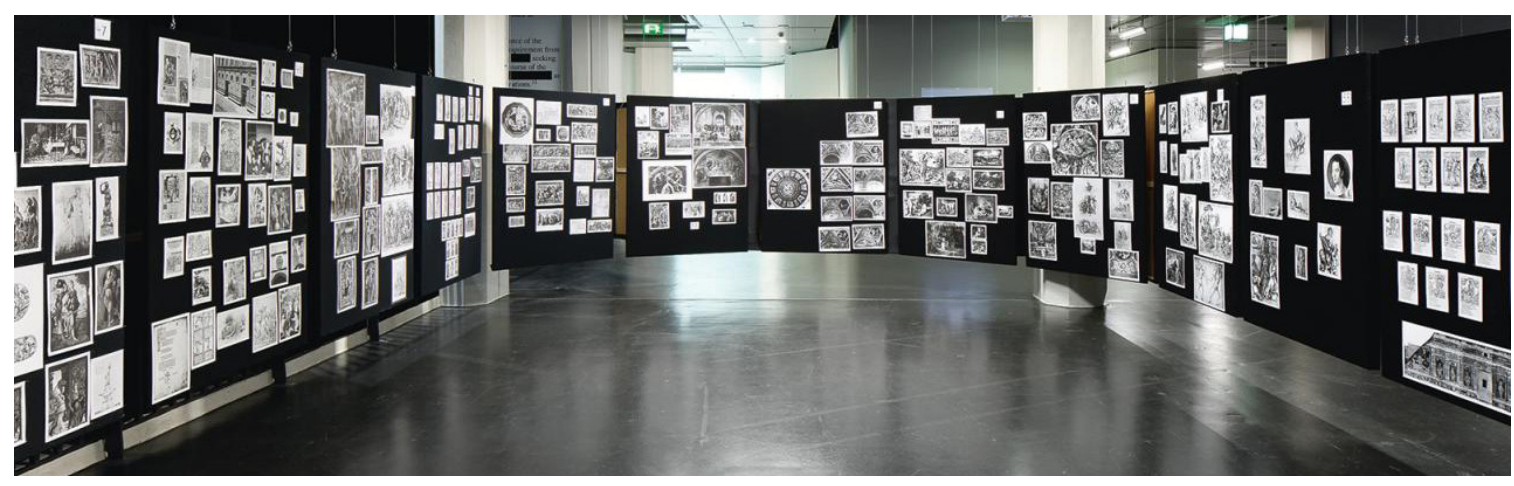

Fig. 2. (Imagen 2) Atlas Mnemosyne, de Aby Warburg (1924-29) (Fuente: ZKM | Center for Art and Media Karlsruhe, foto de Tobias Wootton) 


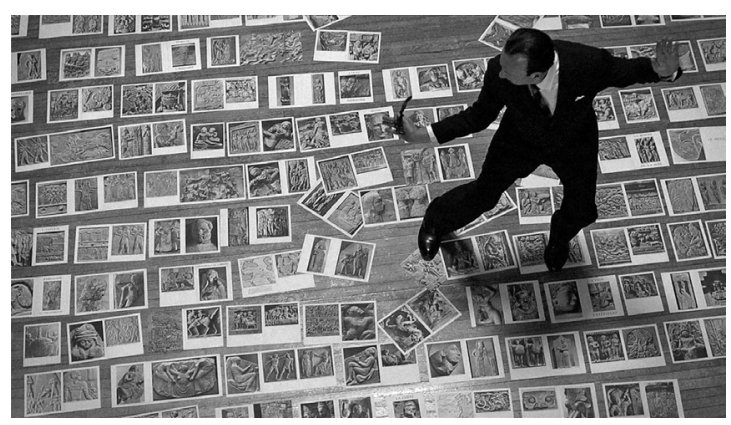

Fig. 3. (Imagen 3) Le Musée Imaginaire, A. Malraux (1947)

paisajística per se, con lógicas propias $\mathrm{y}$ dinámicas particulares a explorar.

- Introducir nuevas variables analíticas que integren la dimensión dinámica y evolutiva del paisaje y permitan incorporar la legibilidad cambiante del mismo a través del tiempo.

- Reivindicar el uso de la imagen, en su concepción más amplia tanto del campo de la fotografía y el medio audiovisual como de la cartografía, como evidencia de investigación e instrumento de análisis paisajística, capaz de correlacionar variables visuales y condiciones físicas y ambientales con relatos conceptuales.

\section{Contexto: el laboratorio a escala real}

Más allá del marco conceptual en el que se sitúa esta investigación, una de sus principales características complementarias deriva de la delimitación de un entorno concreto: el llamado Camp de Tarragona5. En este sentido, con una población aproximada de 500.000 habitantes, este resulta ser un contexto con una evidente vocación de metrópolis discontinua - $\mathrm{o}$, si se prefiere, difusa (Indovina, 1995) y horizontal (Viganó, 2018) de fuertes pulsiones económicas -a veces contradictorias- e intereses cruzados que compiten por el dominio de un espacio acotado y estructura orográficamente legible. En definitiva, un verdadero laboratorio de la contemporaneidad metropolitana cuya lectura de la complejidad es planteada a partir del estudio de los vacíos expectantes y las distintas situaciones de transición como potenciales escenarios de un cambio y transformación que apunte a reequilibrar un territorio de fragmentos y contrastes.

\section{Aproximación metodológica}

"Photographs are perhaps the most mysterious of all the objects that make up, and thicken, the environment we recognize as modern. Photographs really are experience captured, and the camera is the ideal arm of consciousness in its acquisitive mood."

On Photography. Sontag, S. (1973)

Aby M. Warburg (1866-1929) fue un científico cultural hamburgués que basó su carrera profesional en el estudio del arte florentino convirtiéndose en un pionero del análisis de la cultura visual. Sin embargo, entre sus distintos descubrimientos y publicaciones, destaca, por encima de todos, el proyecto al que dedicó los últimos años de su vida, el Atlas Mnemosine6. Construido entre 1924 y 1929, este trabajo consistía en un ensayo gráfico en el que Warburg intentaba, a modo enciclopédico, concentrar el corpus de su conocimiento en una colección de imágenes organizadas entorno a 63 paneles de fondo oscuro. En total, este bilderatlas contenía casi un millar de piezas individuales, mayoritariamente fotografías, aunque también incluyó ilustraciones de libros archivos pictóricos, gráficos originales y recortes de periódico. Su principal voluntad era, por medio del empleo de técnicas de reproducción modernas, construir un verdadero instrumento de conocimiento a partir del uso exclusivo de la imagen.

En este sentido, si bien es cierto que al lector/espectador que hoy revisita su obra, esta puede recordar a una actual búsqueda de algún concepto por Internet mediante el uso de palabras clave y la posterior aparición de un sinfín de imágenes, la verdadera componente de innovación de los paneles de Warburg recae en su doble capacidad de condensar la memoria y estructurar el relato narrativo a partir del planteo de unas constelaciones complejas que establecen interrelaciones entre los elementos individuales y el sistema de imágenes compuestas como un todo. Se trata, pues, de una herramienta centrada en la descubierta y el reconocimiento de valores compartidos entre imágenes que no hacen sino desplegar, por medio de un diálogo continuo entre piezas, una descripción colectiva de los conflictos que, en un contexto y momento 
concretos, derivan en la aceptación colectiva de ciertos significados. En otras palabras, Warburg plantea una metodología inductiva que, como si de un mapa de pistas se tratara, la composición permite iluminar ciertos senderos del pensamiento e hilvanar un relato propio. (Imagen 2)

De este modo, a partir de la obtención de la imagen fotográficacomoindicioprimario, sehan fotografiado varios descampados, terraplenes, ámbitos abandonados y lugares indefinidos del Camp de Tarragona. En concreto, 18 solares o ámbitos territorialmente autónomos. El proceso de selección ha respondido a los siguientes criterios de base: debían ser lugares abandonados sin un uso actual aparente que formaran parte de un ámbito definido dentro de los límites del desarrollo urbano, es decir, cuya expectativa de transformación pudiera ser la causa principal de su estadio expectante. A su vez, se adoptaron los criterios de priorización espacial previamente definidos en el Plan Territorial Parcial del Camp de Tarragona cuya aprobación definitiva tuvo lugar en 2010. Esto derivó en el estudio en detalle de los paisajes del vacío situados, mayoritariamente, alrededor del triángulo definido por las ciudades de Reus, Tarragona y Vila-seca, el ámbito de mayor pulsión urbana y productiva donde las grandes industrias químicas conviven con el creciente motor turístico y la renqueante actividad agrícola de un llano tan fértil como frágil dominado por la potente red infraestructural que, de manera simultánea, conecta y fragmenta por igual.

Acto seguido a esta (re)colección de imágenes, estas se reprodujeron a tamaño 10x15 (formato postal o fotografía estándar) y a color permitiendo, con ello, distribuir, a la manera inclusiva de Malraux, todos los elementos en una constelación única de múltiples relaciones. (Imagen 3)

No obstante, el ejercicio no era completo y, al igual que Warburg, cabía forzar el diálogo entre todas las fotografías cuestionándolas, a partir de los indicios que activaban el mecanismo semiológico de la comunicación y la memoria alrededor de los conceptos planteados. De este modo, segmentando grupos, estableciendo series y proponiendo etiquetas se empezó a esbozar una primera versión de este renovado bilderatlas acerca de los paisajes transitivos.

\section{Taxonomía del vacío expectante}

La taxonomía es la ciencia que trata de los principios, métodos y fines de la clasificación ordenada, jerarquizada y sistemática de grupos dentro de una disciplina. En este caso, esta técnica es la herramienta clave sobre la que se fundamentó el grueso de este ejercicio $\mathrm{y}$, como si de un estudio estadístico con las características visuales como variables de investigación se tratara, cada imagen fue escrutada en aras de identificar patrones y rasgos asociados. Éstos se listaron ponderando el peso de cada aspecto relevante. Se buscaron las dominantes, se agruparon en conjuntos con una tónica coherente y se eliminaron provisionalmente aquellas imágenes huérfanas de grupo. Tras pruebas previas con paneles de fondo negro, finalmente cada conjunto de imágenes se organizó en tableros de fondo claro que permitía, por contraste cromático, valorar el conjunto con una mayor nitidez visual. Se repitió la operación dos veces más iterando el proceso depurando, con ello, la coherencia de los resultados.

En paralelo, si bien no se modificó la medida de ninguna de las fotografías, se adaptó su posición relativa para igualar los horizontes, establecer series cromáticas o insinuar paquetes y subgrupos.

De este modo, la caracterización de los espacios vacíos del Camp de Tarragona se organizó entorno a los siguientes conceptos o capítulos: ejes, trazos y líneas de tensión; límites, fronteras y cul-de-sacs; nudos, puentes e intraestructuras; asfalto y materialidad; energyscapes, groundscapes, muros y recintos; residuos y contaminación; latencia y anonimato. Las siguientes imágenes (ver 4 a 19) dan cuenta de este nuevo atlas fotográfico de los paisajes transitivos poniendo de relieve, como ya se anticipaba en la introducción, el interés que despierta la ambigüedad de estos lugares. (Imágenes 4-19)

\section{Reflexión abierta y esbozos de futuro}

"Fragment indécidé du jardin planétaire, le Tiers paysage est constitué de l'ensemble 


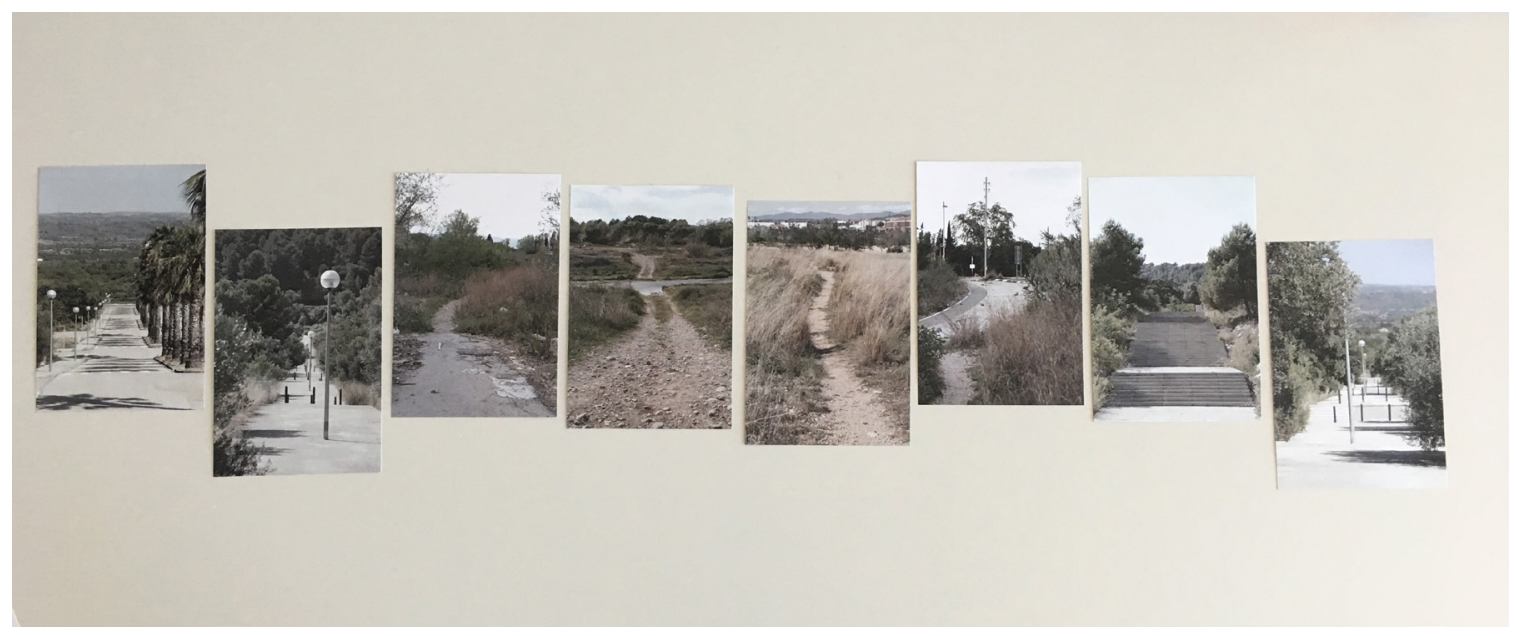

Fig. 4. (Imagen 4) Trazos indecisos (Solé, 2019)

des lieux délaissés par l'homme. Ces marges assemblent une diversité biologique qui n'est pas à ce jour repertoriée comme richesse. Tiers paysage renvoie à tiers - état (et non à Tiers - monde). Espace n'exprimant ni le pouvoir ni la soumission au pouvoir. Il se réfère au pamphlet de Siesyes en 1789 : " Qu'est - ce que le tiers-état? - Tout. Qu'a$t$ - il fait jusqu'à présent? - Rien. Qu'aspire - $t$ - il à devenir? - Quelque chose".

Manifest du Tier Paysage. Clément, G. (2004)

Seguramente, el principal valor de esta investigación recae, hasta el momento, en el descubrimiento de la vigencia conceptual de la cuestión esbozada en un entorno rico en terrains vagues y la construcción del atlas fotográfico de los mismos. De este modo, la primera revisión sistemática de la literatura ha desvelado una serie de autores, conceptos y tendencias entorno a la noción del vacío expectante que la colección de imágenes sistemáticamente ordenadas ha estructurado y apuntalado. Fruto de ello, algunas primeras conclusiones emergen con cierta claridad. En todos estos paisajes pesa sobremanera la horizontal, sinónimo de abandono y el dominio de lo natural por encima de la vertical como símbolo de la acción humana, del proyecto y la acción. Son, pues, lugares dominados por un horizonte permanente, sólido, como principal referente visual. Suelo y cielo como dicotomía simplificada de una ecuación mucho más compleja.

En este sentido, la segunda de las conclusiones hace referencia al propio título de la comunicación, paisajes transitivos, que, a nuestro parecer, cobra todo el sentido en la exploración de estos lugares expectantes. Las imágenes muestran, en términos de gramática urbana, una oración incompleta. No presenta sujeto o, en el mejor de los casos, éste viene desdibujado en varios fondos de inversión, grandes corporaciones inmobiliarias $\mathrm{u}$ otras fuentes de capital anónimo. También carece de predicado. O bien es ausente a la espera de una realidad prometida que nunca llegó o bien, en muy pocos casos, responde a un verbo circunstancial, a un uso provisional no reconocido en el planeamiento. No obstante, su posición relativa y estratégica, sumada a la libertad inherente de un porvenir por escribir invitan a pensar en estructuras gramaticales complejas que esperan completar su rol relevante en el territorio mediante complementos directos a descubrir. Cabrá identificarlos y arroparlos con otros complementos circunstanciales. Lugar, tiempo, modo, cantidad o causa aparecen como nuevas incógnitas de una ecuación variable que deberían permitir caracterizar los valores de cada uno de estos paisajes.

Para hacerlo, esta investigación presenta unas líneas de trabajo futuras sobre las que se inscriben los siguientes pasos metodológicos a seguir a tal efecto. El primero de ellos sería ampliar la exploración bibliográfica de los conceptos y definiciones a partir de depurar la revisión sistemática iniciada que debería incorporar nuevos autores, casos, métodos y técnicas analíticas relevantes 


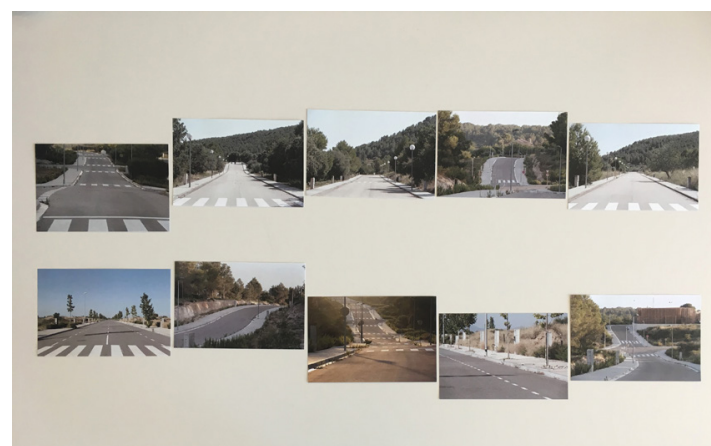

Fig. 5. (Imagen 5) Urbanizaciones incompletas (Solé, 2019)

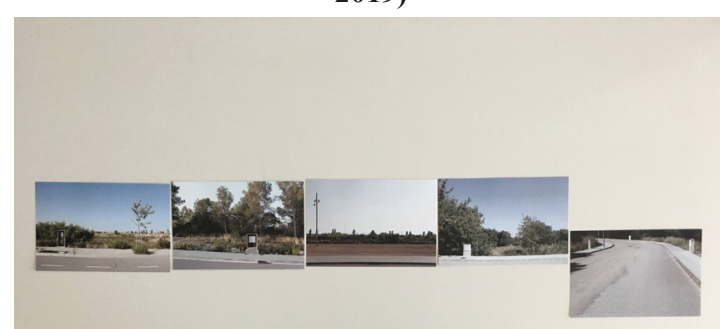

Fig. 6. (Imagen 6) Límites imprecisos (Solé, 2019)

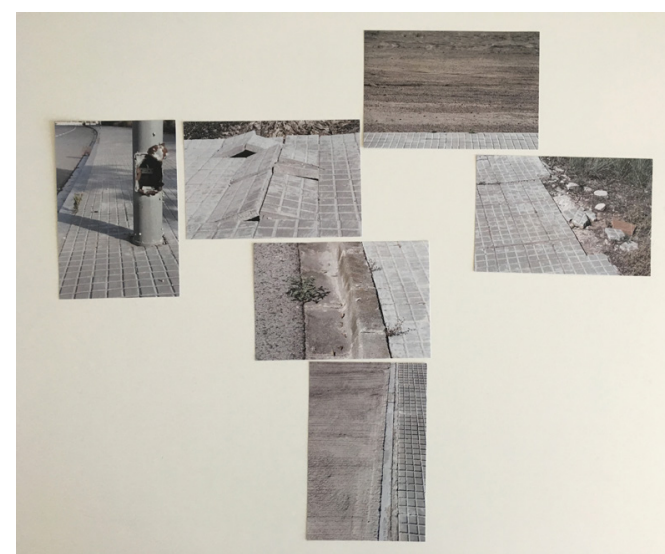

Fig. 7. (Imagen 7) Grietas en el asfalto (Solé, 2019)

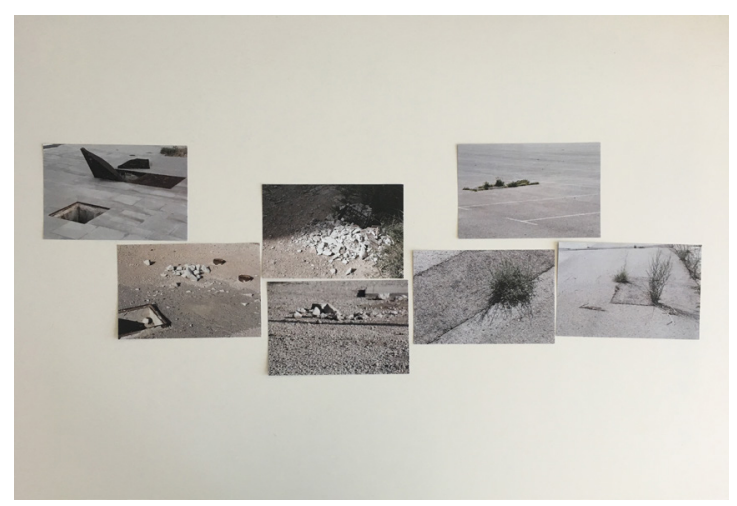

Fig. 8. (Imagen 8) Materialidades del desperdicio (Solé, 2019)

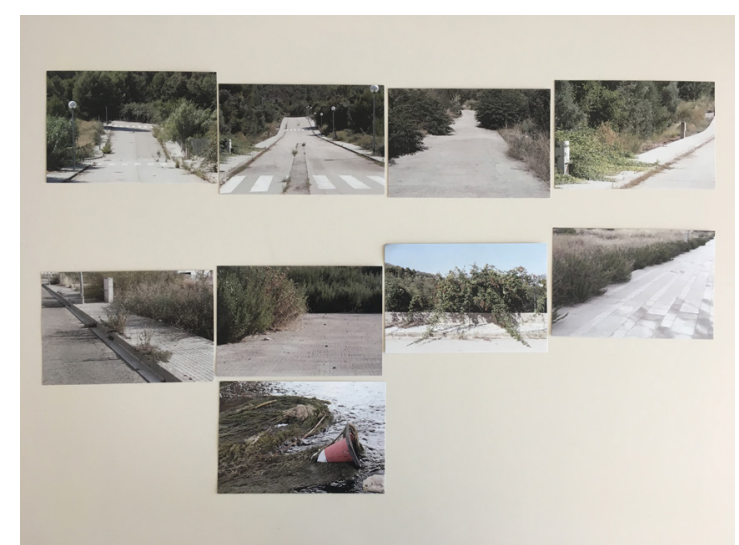

Fig. 9. (Imagen 9) La Reconquista del verde (Solé, 2019)

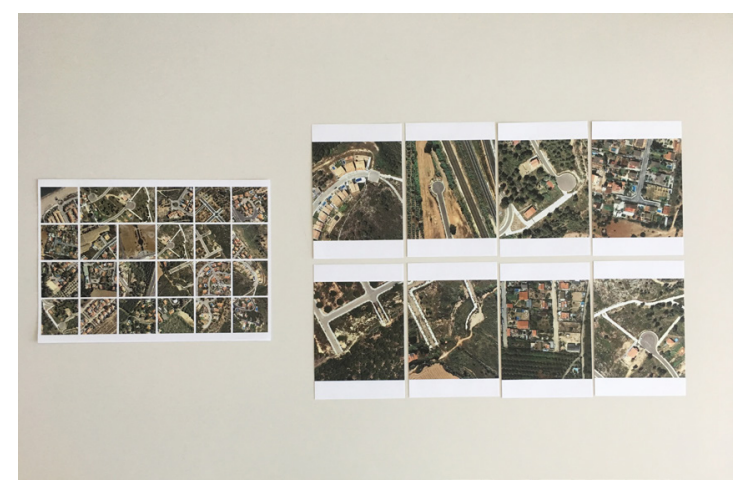

Fig. 10. (Imagen 10) Finales abruptos (Solé, 2019)

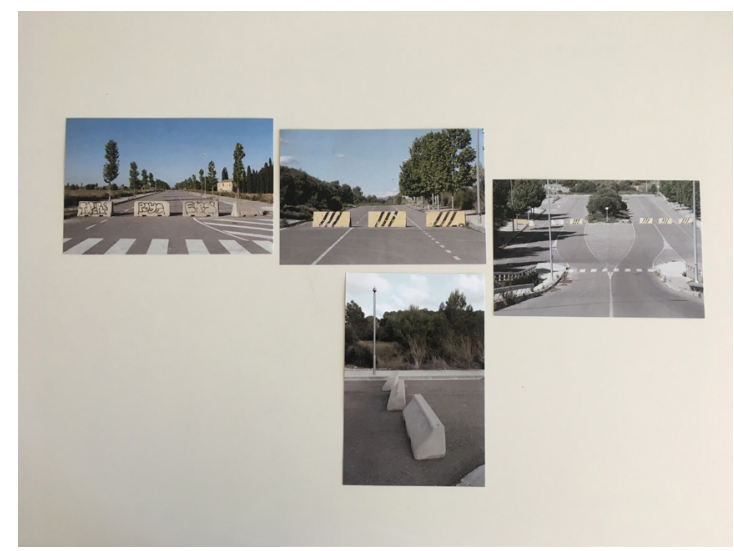

Fig. 11. (Imagen 11) Paisajes prohibidos (Solé, 2019) 


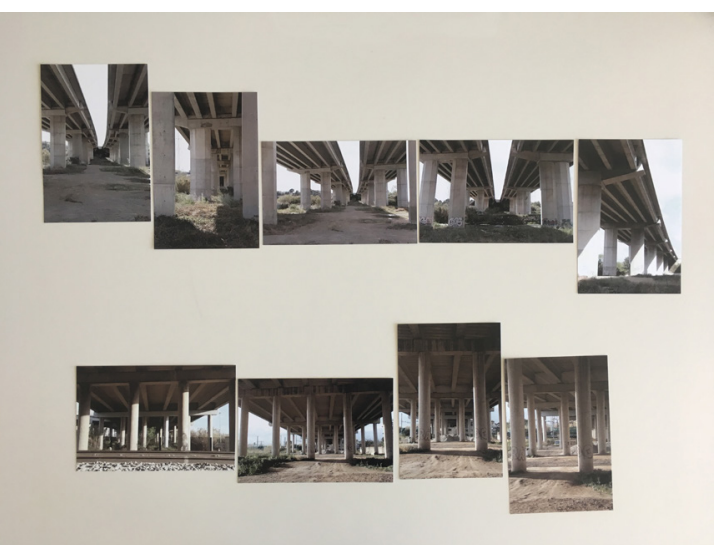

Fig. 12. (Imagen 12) Las arquitecturas de la movilidad (Solé, 2019)

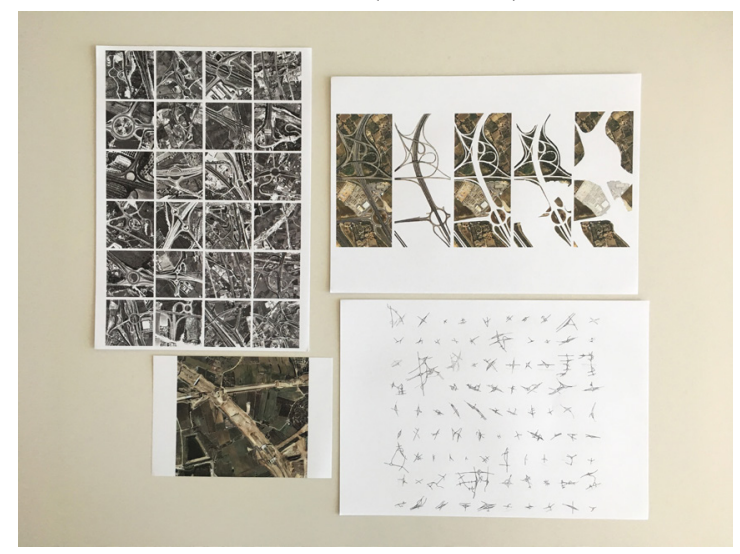

Fig. 13. (Imagen 13) Nudos, lazos y líos (Solé, 2019)

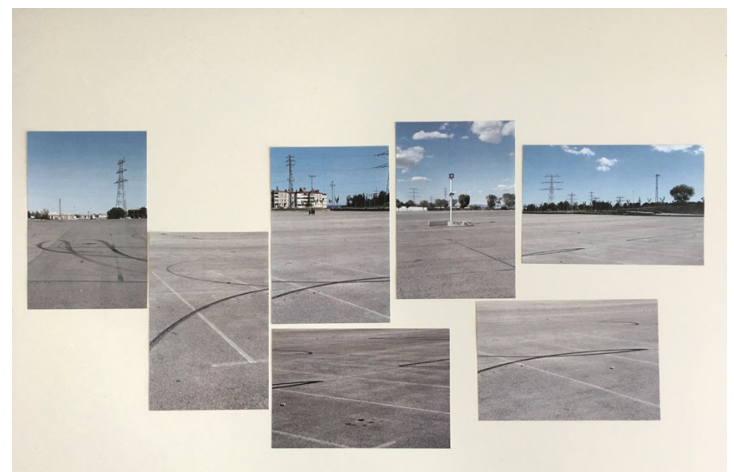

Fig. 14. (Imagen 14) Vacío infinito (Solé, 2019)

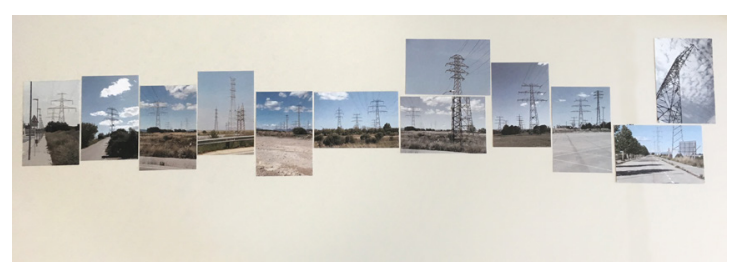

Fig. 15. (Imagen 15) Energyscapes (Solé, 2019)

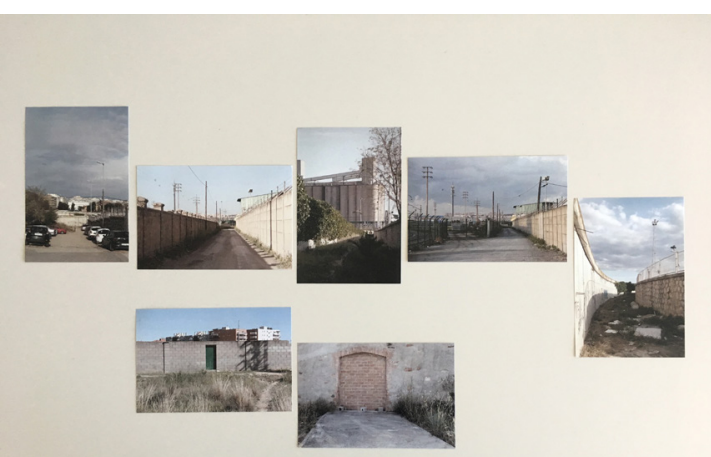

Fig. 16. (Imagen 16) Recintos y murallas (Solé, 2019)

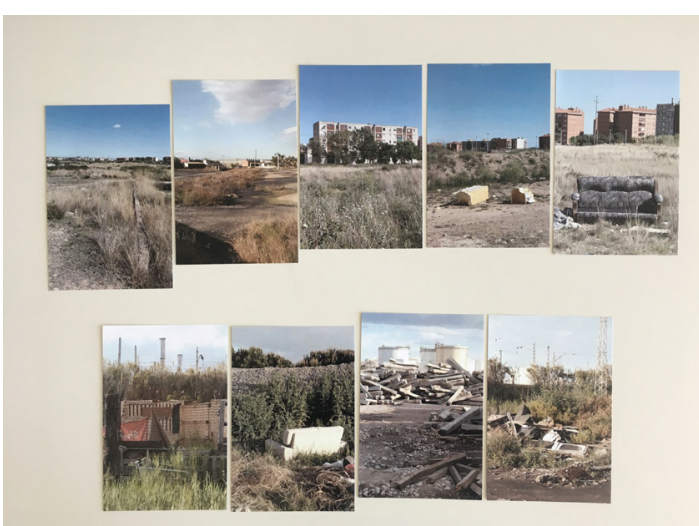

Fig. 17. (Imagen 17) Los paisajes del abandono (Solé, 2019)

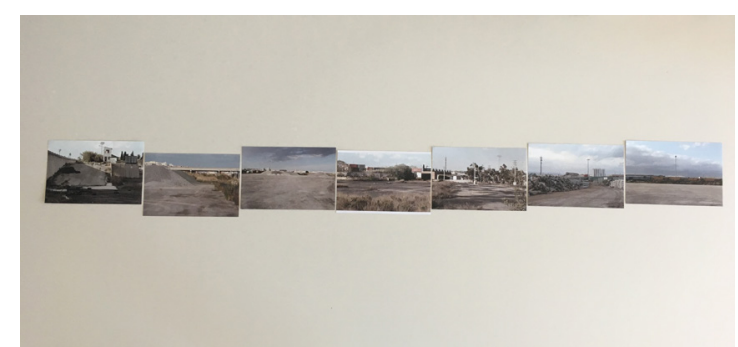

Fig. 18. (Img.18) Horizontes del olvido (Solé, 2019)

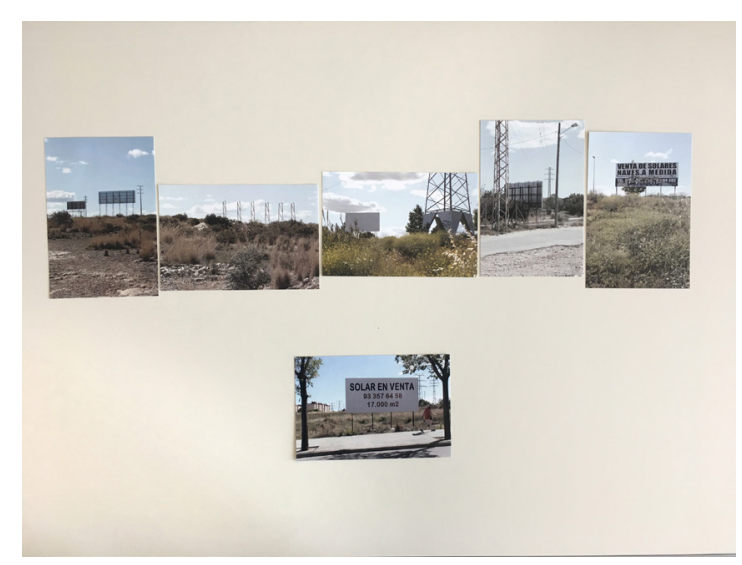

Fig. 19. (Img.19) La promesa eterna (Solé, 2019) 
y pertinentes. El segundo, parcialmente elaborado, sería completar el atlas por medio de una serie de cartografías temáticas que permitan acotar estos paisajes y especificar sus valores integrando criterios de análisis tanto cuantitativos como cualitativos. Por último, con respecto a la caracterización del potencial de transformación y mejora territorial de estos ámbitos, este estudio plantea la voluntad de comparar los casos del Camp de Tarragona con otras situaciones asimilables de ámbito estatal o internacional con el fin de explorar propuestas replicables en nuestro contexto.

En definitiva y a modo de conclusión global, esta investigación parece poner el foco en los límites desdibujados de la ciudad compacta y la ciudad difusa, precisamente en los lugares indecisos donde el modelo tradicional de hacer urbanismo y ordenar el territorio entra en crisis, donde el vacío se convierte en el principal potencial de proyecto, donde el tiempo, aparentemente congelado, propone una lectura dinámica de un proceso continuo y evolutivo, en transición, transitivo, hacia unas opciones de futuro por descubrir, ensayar y estudiar.

\section{Agradecimientos:}

La investigación de esta ponencia se ha financiado mediante el Ministerio Español de Ciencia, Innovación y Universidades a través de su proyecto de investigación CHORA (CSO2017-82411-P) y AEI/FEDER,UE $\mathrm{y}$ por el Departmento de Investigación y Universidades del Gobierno Catalán por medio del grupo 2017SGR22.

\section{Notas}

1 Según De Solà-Morales, M. (1987) “(...) hijo de la complejidad y la superposición, el Proyecto Urbano es partir de la geografía de la ciudad dada, de sus solicitudes y sugerencias, e introducir con la arquitectura elementos de lenguaje que den forma al lugar. Implica confiar más en la complejidad de la obra a hacer que en la simplificación racional de la estructura urbana. Es también trabajar de forma inductiva, generalizando lo particular, lo estratégico, lo local, lo generativo y el modelo". En otras palabras, el Proyecto Urbano es un campo de trabajo intermedio donde las escalas se entrelazan y donde el arquitecto es autoridad razonable en la forma de la ciudad precisamente porque hace arrancar de la edificación arquitectónica la transformación del entorno a partir de tomar la vivienda como material urbano por excelencia, convertir el barrio en la nueva escala de referencia, renovar el concepto del centro-urbano y confiar en la estrategia de trazado de calles como forma conocida de ordenar sectores urbanos de tamaño medio.

2 En su libro The Mystery of Capital, De Soto, H. (2001), el economista peruano desgrana algunos de los principales aspectos que correlacionan elementos intangibles como la propiedad o el valor del suelo con la mejora tangible del espacio construido demostrando, con ello, el potencial de desarrollo de métodos que permitan desvelar, medir y cuantificar el valor de dicho capital.

3 De hecho, según Joanne Lee (2018), el concepto "terrain vague" aparece, por primera vez, en la novela Les Miserables de Victor Hugo (1872) para describir un contexto de carácter "anfibio" que existía en algún lugar entre la ciudad y el mundo rural.

4 "Intraestructuras", las llamaba Manuel de Solà-Morales (2009) en la revista AT\#19 El Camp.

5 El Camp de Tarragona, entendido como la unidad paisajística, formal y funcional territorial conformada per la fértil llanura que dibujan las comarcas catalanas del Tarragonès, Baix Camp y Alt Camp, entre el mar Mediterráneo y la sierra de Prades. Continuamente llamado a ser "la segunda área metropolitana de Cataluña", el Camp es un territorio que durante la segunda mitad del siglo XX ha sufrido profundas transformaciones físicas y socioeconómicas que lo convierten en un entorno situaciones de desencanto urbanístico se traducen en una amplia colección de ámbitos vacíos que reivindican, a través de su posición territorial y sus condiciones primigenias, tanto su vigencia como objetos de estudio como su elevado valor como paisajes transitivos.

6 Como patrona de su gran proyecto vital, Warburg elige Mnemosine, la diosa griega de la memoria y madre de las musas. 


\section{Referencias}

Clément, Gilles. 2003. Le Tiers Paysage. Paris : Editions Sujet/Objet

De Solà-Morales, Ignasi. 1995. "Terrain Vague". En Anyplace, Anyone Corporation, 118-23. New York, Cambridge: The MIT Press.

De Solà-Morales, Manuel. 1987. "La segunda historia del Proyecto Urbano" en Revista UR 5, 21-27. ISSN: 0213-1110. Barcelona: Laboratori d'Urbanisme de Barcelona (LUB). 2009. "Un camp de coses (els buits de la metròpolis)". Tarragona: Revista AT 19 (1): $3 \mathrm{p}$

De Soto, H. 2001. The Mystery of Capital. Why Capitalism Triumphs in the West and Fails Everywhere Else. London: Bantam Press.

Goula, M. 2006. Los otros paisajes. Lecturas de imagen variable. Tesis doctoral UPC. Director: De Solà-Morales, M. Barcelona: Departamento de Urbanismo y Ordenación del Territorio.

Heynen, Hilde. 1992 "The Peripherial Condition. Some thoughts about a problematic phenomenon, illustrated by case study in Winterslag". Barcelona: Revista UR 9-10: 57-59 p. Proyectar la periferia, Laboratori d'Urbanisme ETSAB-UPC.

Lee, Joanne. 2010. "Vaguely Northern: in between in England". En Northern Light. Landscape, Photography and Evocations of the North, 133-42. Biefield: Transcript.

Montejano, J. Antonio. 2010. Metropolización del Territorio y Regiones Urbanas Medias. El caso del ámbito central del Camp de Tarragona, 1977-2008. Tesis Doctoral. Director: Antonio Font. Barcelona: ETSABUPC.

Muñoz, F. 2008. Urbanalización. Paisajes comunes, lugares globales. Barcelona: Gustavo Gili, 2008

Sassen, S. 2001. The Global City. New York, London, Tokyo. New Jersey: Princeton University Press

Walker, E., 2010. Lo Ordinario. Barcelona: Gustavo Gili, 2010.

Warburg, A. (1929). The Atlas Mnemosine. Publicado en 2000 como Der Bilderatlas: Mnemosyne in Warburg's Gesammelte
Schriften, II.1. Berlin: Akademie Verlag. Zaguirre Fernández, Juan Manuel. 2017. Vías y Entrevías. Atributos y compromisos del distrito industrial de Tarragona. Tesis Doctoral. Director: Josep Parcerisa. Barcelona: ETSAB-UPC. 